\title{
Entwicklung polymerbeschichteter DNA-Chip-Oberflächen für enzymatisch unterstützte Genotypisierungen
}

Caroline Hiller ${ }^{1}$, Alfred Kick², Beate Katzschner², Mareen Müller ${ }^{1}$, Martin Bönsch², Jan Voigt ${ }^{3}$, Dietmar Appelhans ${ }^{4}$, Werner Brabetz ${ }^{1}$, Martin Jung ${ }^{1}$, Michael Mertig ${ }^{2,3}$

${ }^{1}$ Biotype Diagnostic GmbH, Moritzburger Weg 67, 01109 Dresden

${ }^{2}$ Professur für Physikalische Chemie, Mess- und Sensortechnik, Technische Universität Dresden, 01062 Dresden

${ }^{3}$ Kurt-Schwabe-Institut für Mess- und Sensortechnik e.V. Meinsberg, Kurt-Schwabe-Straße 4, 04720 Ziegra-Knobelsdorf

${ }^{4}$ Leibniz-Institut für Polymerforschung Dresden e.V., Hohe Str. 6, 01069 Dresden

\section{Zusammenfassung}

Wir stellen die Entwicklung von Polymerbeschichtungen auf Glasoberflächen vor, welche die Analyse geringer DNA-Mengen durch die Methode der ALR (Arrayed Ligation Reaction) ermöglicht. Dieses Verfahren wurde für den spezifischen Nachweis von Schimmel- und Hausfäulepilzen bei der Biotype Diagnostic GmbH etabliert.

\section{Einleitung}

Die DNA-Chiptechnologie bildet einen innovativen und effizienten Ansatz in der genetischen Diagnostik. Für diese Technologie stellen wir die Entwicklung von Polymerbeschichtungen auf Glasoberflächen vor, welche die Analyse geringer DNA-Mengen durch die Methode der ALR (Arrayed Ligation Reaction) ermöglicht. Dieses Verfahren wurde für den spezifischen Nachweis von Schimmel- und Hausfäulepilzen bei der Biotype Diagnostic GmbH etabliert (Tafel 1). Neben der Hybridisierung komplementärer DNA-Stränge findet dabei eine spezifische Enzymreaktion statt, bei der ein fluoreszenzmarkiertes DNA-Oligonukleotid kovalent an immobilisierte DNA-Sonden des Mikroarrays und damit an den DNA-Chip gebunden wird (Bild 1). Diese Ligationsreaktion findet jedoch nur statt, wenn die DNA-Zielsequenz zur Sonde und zum Ligationsoligonukleotid komplementär ist. [1-3]

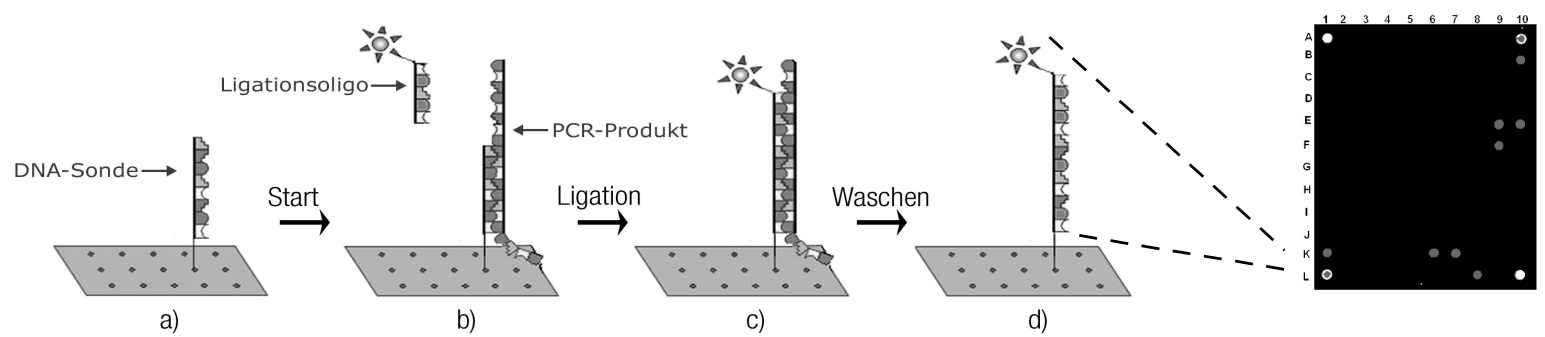

Bild 1 Darstellung der ALR auf einem Mikroarray. a) Produktfertige DNA-Chips; b) Hybridisierung des PCR-Produkts an die komplementäre DNA-Sonde; c) Ligation des fluoreszenzmarkierten Ligationsoligonukleotids an die DNASonde; d) Waschen der DNA-Chips. 
Für diesen spezifischen Nachweis wird eine Beschichtung der Glasobjektträger entwickelt, die eine unspezifische Adsorption der Ligase und insbesondere der fluoreszenzmarkierten Ligationsoligonukleotide verhindert. Zugleich muss eine geeignete Oberfläche für die Enzymreaktion geschaffen werden, die eine genügend hohe Sondendichte aufweist und so einen spezifischen und sensitiven Nachweis erlaubt. Die gewünschte Hydrophobizität der Oberfläche ist so zu gestalten, dass die Enzymreaktion nicht beeinträchtigt wird.

Tafel 1 Mit dem MYCOTYPE ${ }^{\circledR}$ BASIDIO $^{\text {QS }}$ MicroARRAY Detection KIT nachweisbare Hausfäulepilze. ${ }^{1)}$

\begin{tabular}{|c|c|}
\hline Wissenschaftlicher Name & Deutscher Name \\
\hline Antrodia sinuosa & Schmalsporiger Weißer Porenschwamm \\
\hline Antrodia vaillantii & Breitsporiger Weißer Porenschwamm \\
\hline Antrodia xantha & Gelber Porenschwamm \\
\hline Bjerkandera adusta & Angebrannter Rauchporling \\
\hline Coniophora arida & Trockener Kellerschwamm \\
\hline Coniophora marmorata & Marmorierter Kellerschwamm \\
\hline Coniophora olivacea & Olivbrauner Kellerschwamm \\
\hline Coniophora puteana & Brauner Kellerschwamm \\
\hline Daedalea quercina & Eichenwirrling \\
\hline Donkioporia expansa & Ausgebreiteter Hausporling \\
\hline Fomitopsis pinicola & Rotrandiger Baumschwamm \\
\hline Gloeophyllum abietinum & Tannenblättling \\
\hline Gloeophyllum sepiarium & Zaunblättling \\
\hline Laetiporus spp. & Schwefelporlinge \\
\hline Leucogyrophana mollusca & Sklerotien Hausschwamm \\
\hline Leucogyrophana pinastri & Gelbrandiger Hausschwamm \\
\hline Neo/Lentinus lepideus & Schuppiger Sägeblättling \\
\hline Oligoporus placenta & Rosafarbener Saftporling \\
\hline Phellinus ferruginosa & Rostbrauner Feuerschwamm \\
\hline Pleurotus spp. & Seitlinge \\
\hline Schizophyllum commune & Gemeiner Spaltblättling \\
\hline Serpula himantioides & Wilder Hausschwamm \\
\hline Serpula lacrymans & Echter Hausschwamm \\
\hline Stereum hirsutum & Zottiger Schichtpilz \\
\hline Stereum spp. & Schichtpilze \\
\hline Tapinella panuoides & Muschelkrempling \\
\hline Trametes versicolor & Schmetterlingsporling \\
\hline
\end{tabular}

${ }^{1)}$ Es wurden entsprechende, spezifische DNA-Sonden und Primer bzw. Template verwendet.

\section{Material und Methoden}

\subsection{Beschichtung der Glasobjektträger}

Objektglasträger aus Kalknatronglas (Menzel) wurden in Ethanol und in entionisiertem Wasser (je 5 min im Ultraschallbad) und 10 min in Luft-Plasma gereinigt. Anschließend wurde eine die Glasoberfläche mit 3Glycidoxypropyltrimethoxysilan (GOPS) aus der Gasphase beschichtet.

Verzweigtes Polyethylenimin (PEI, CAS-Nummer: 9002-98-6) wurde an die GOPS-Oberfläche aus 0,1 \%iger Lösung $(0,1 \mathrm{M}$ Natriumborat, $\mathrm{pH}=9)$ gebunden. Die Aktivierung der Aminogruppen erfolgte anschließend aus wässriger Lösung mit $25 \mathrm{mM}$ 1-Ethyl-3-(3-dimethylaminopropyl)carbodiimid $(\mathrm{EDC} \cdot \mathrm{HCl})$ und 25 mM N-Hydroxysuccinimid (NHS). 


\subsection{Immobilisierung der DNA-Sonden}

Amino-modifizierte DNA-Sonden (50 $\mu \mathrm{M}$ in $50 \mathrm{mM}$ Natriumphosphat, 0,001\% Natriumdodecylsulfat) wurden mittels eines Mikropipettiersystems (Nano-Plotter, GeSiM mbH) auf den beschichteten Glasobjektträgern immobilisiert. Dabei wurden Tropfen mit einem Volumen von etwa $400 \mathrm{pl}$ abgesetzt. Danach wurden die Chips in einer Feuchtekammer übernacht inkubiert, mit entionisiertem Wasser gewaschen und mit $100 \mathrm{mM}$ Tris(hydroxymethyl)-aminomethan und $50 \mathrm{mM}$ Ethanolamin $(\mathrm{pH}=9)$ geblockt.

\subsection{ALR}

Es wurde das MYcotyPE ${ }^{\circledR}$ BASIDIO ${ }^{\text {QS }}$ Microarray Detection KIT verwendet und die ALR entsprechend dem vom Hersteller beschriebenen Protokoll durchgeführt. Als Template für die ALR-Experimente wurden zum einen äquimolare Gemische der PCR-Amplifikate aller detektierbaren Pilze, sowie Gemische synthetisch hergestellter Template eingesetzt (Tafel 1).

\section{Ergebnisse und Diskussion}

Verschiedene Ansätze zur Immobilisierung aminomodifizierter Oligonukleotide ( $\mathrm{NH}_{2}$-DNA) wurden untersucht. Einerseits erfolgte eine Beschichtung durch Silanisierung der Glasobjekträger mit GOPS (Bild 2 links), andererseits wurde zusätzlich eine Polymerbesichtung und Aktivierung in Form von N-Hydroxysuccinimidestern (NHS-Ester, Bild 2 rechts) vorgenommen.

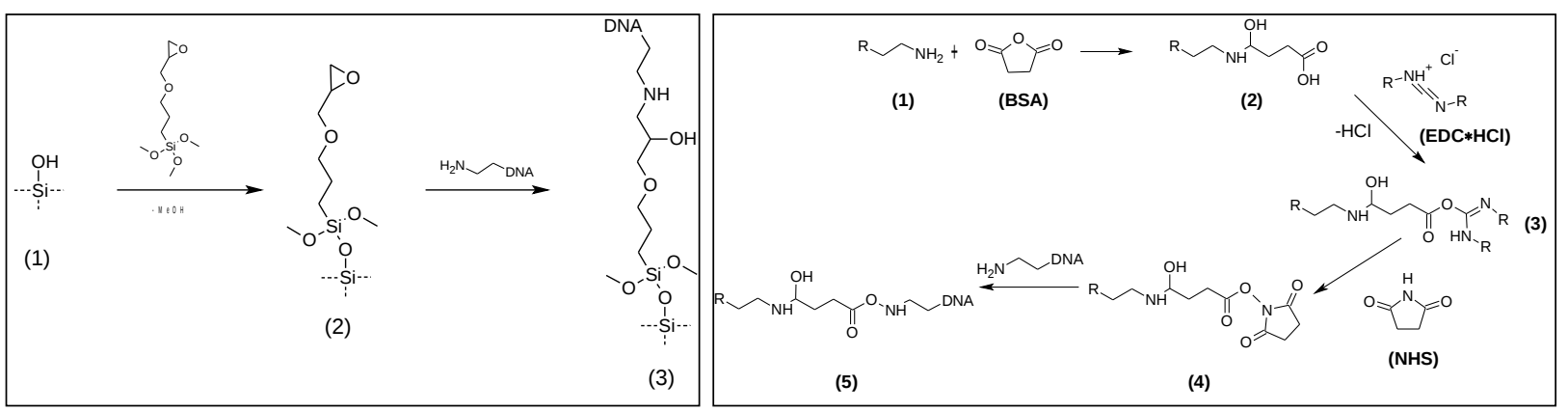

Bild 2 Links: Anbindung aminomodifizierter Oligonukleotide an eine GOPS-Oberfläche. GOPS wird an freie SiOHGruppen (1) gebunden. Aminomodifizierte Oligonukleotide binden an Epoxidgruppen (2). Rechts: Aminogruppen (1) der Oberfläche werden mit Bernsteinsäureanhydrid (BSA) zu Carboxylgruppen (2) umgesetzt, mit 1-Ethyl-3-(3-dimethylaminopropyl)carbodiimid $(\mathrm{EDC} \cdot \mathrm{HCl})$ aktiviert und mit NHS verestert (4). Aminomodifizierte Oligonukleotide binden an NHS-Ester (5).

Die Fluoreszenzsignale nach der ALR sind für diese zwei Beschichtungen in Bild 3 dargestellt. Die Spotgrößen der beiden Mikroarrays unterscheiden sich deutlich. Die Silanisierung (Bild 3, links) erzeugt eine Oberfläche, die schlechter benetzt als es durch die Beschichtung mit PEI der Fall ist (Bild 3, rechts). 

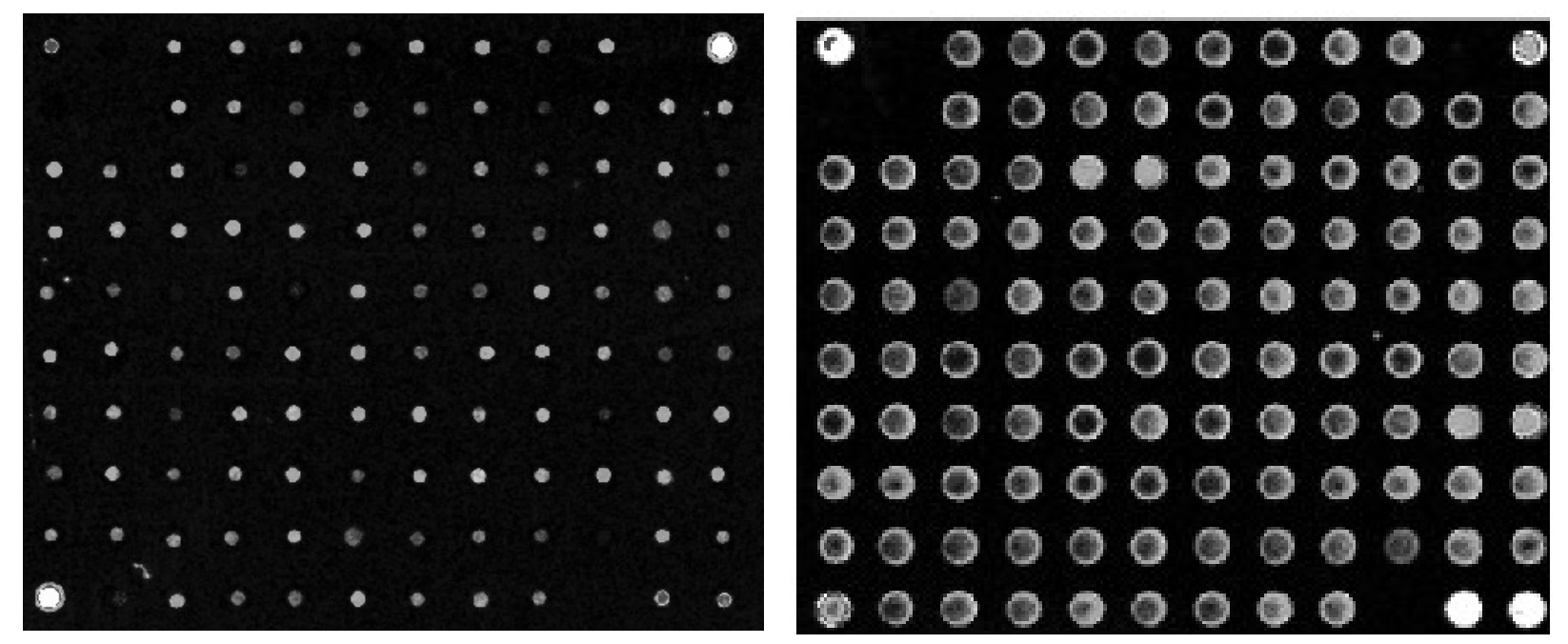

Bild 3 Fluoreszenzbild nach der ALR auf einem mit GOPS (links) und auf einem mit GOPS/PEI/NHS (rechts) beschichteten Chip.

Für die ALR erwies sich die PEI-Beschichtung als am besten geeignet. Durch diese konnte eine Verbesserung der Immobilisierung der Sonden, der Benetzung der Oberfläche, der Enzymreaktion und somit höhere Signalstärken erreicht werden.

\section{Danksagung}

Die diesem Artikel zugrunde liegenden Forschungsarbeiten werden durch die Sächsische AufbauBank (FKZ: 14119/2447 und 14120/2447) gefördert.

\section{Literatur}

[1] E. Busti, R. Bordoni, B. Castiglioni, P. Monciardini, M. Sosio, S. Donadio, C. Consolandi, L. Rossi Bernardi, C. Battaglia, G. De Bellis: BMC Microbiol. 20 (2002) 2:27.

[2] S. Case-Green, C. Pritchard, E. Southern: Methods Mol. Biol. 226 (2003) 255-269.

[3] Kurg A, Tõnisson N, Georgiou I, Shumaker J, Tollett J, Metspalu A: Genet. Test. 4 (2000) 1-7. 